\title{
Comparativa de la aplicación del método del caso en dos modalidades docentes distintas de la misma asignatura: presencial y docencia inversa.
}

\author{
Juan Vicente Oltra Gutiérrez ${ }^{a}$
}

${ }^{a}$ Escuela Técnica Superior de Ingeniería Informática. Universitat Politècnica de València. jvoltra@omp.upv.es

\begin{abstract}
In the present work the differences in results as well as in participation are studied (using gamification activities to measure this) that come from the use of the cas method, a method that in itself is not exactly an educational innovation, due to its long history, but that the adaptation to different teaching modalities presents some singularities of interest.
\end{abstract}

Keywords: educational innovation, case method, flip teaching, gamification

\section{Resumen}

En el presente trabajo se estudian las diferencias tanto en resultados como en participación (usando para medir esta las actividades de gamificación) que devienen del empleo del método del caso, método que en sí mismo no es precisamente una innovación educativa, por su larga historia, pero que la adaptación a distintas modalidades docentes presenta algunas singularidades de interés.

Palabras clave: innovación educativa, método del caso, docencia inversa, gamificación.

\section{Introducción}

En la presente comunicación se analiza el impacto del uso del método del caso en una asignatura de corte jurídico que cubre aspectos legales y deontológicos, realizando una comparativa de sus resultados en dos modalidades distintas: en los grupos puramente presenciales, frente al grupo cuya docencia se desarrolla como «Flip Teaching» o docencia inversa, términos ambos empleados institucionalmente por la Universitat Politècnica de València y que emplearemos indistintamente como sinónimos.

Tras un breve repaso a los antecedentes, en un segundo punto daremos cuenta de los objetivos del trabajo actual para, en los dos apartados siguientes, trazar el desarrollo de la experiencia y presentar los resultados. Concluiremos con unas breves conclusiones y las referencias bibliográficas empleadas.

\subsection{Antecedentes. EI método del caso.}

Ya desde mucho tiempo atrás, el método del caso se usó en distintas materias y niveles educativos. Quizá, al tratarse de una asignatura con una importante carga jurídica, e impartida por el Departamento de Organización de Empresas, el origen del método parece avalar su introducción en la misma. Si seguimos a Toller, que estudió sus orígenes históricos (TOLLER, 2005), aunque se suele cifrar su origen en los años 30 del siglo XX en la Harvard Business School (HBS), se sabe que de forma previa existieron precedentes en el uso del método del caso para la enseñanza del comercio y los negocios en Francia y Alemania, y no solo ahí. De hecho el origen en la HBS del uso del caso como herramienta pedagógica vino de la mano del Decano de Wallace B. Donham, graduado de la Harvard Law School que llevó a la enseñanza de la administración el método de debate que ya se usaba en la Facultad de Derecho, donde lo había aprendido. $\mathrm{Y}$ es que en el mundo jurídico su historia se remonta a mucho tiempo atrás: en las 
escuelas de derecho de los siglos XVI a XVIII existía la idea de que el Derecho se aplica a hechos variables, porque se trata del arte problemático de decidir y resolver los casos que se van suscitando, lo que provocó el retorno del método del debate, verdadero sustento de la enseñanza medieval, a su vez heredero de la dialéctica griega y el método socrático. Como se puede comprobar, hablamos de algo muy anterior al siglo XX en lo relativo a los aspectos legales. La otra parte importante de la asignatura tiene un corte deontológico y cabe preguntarse por el uso del método para estos temas. En este punto, de acuerdo con (ARGANDOÑA RAMIZ, 1999), dado que un caso es la descripción de una situación real de dirección que suele implicar habitualmente un reto, decisión o problema, centrado en historia que permite cierta empatía con los sujetos principales del caso, se aleja de la "casuística", basada en la aplicación de soluciones dictadas por una ciencia o técnica, como los ejercicios que pueden emplearse desde la física a la contabilidad, que resultan útiles para la transmisión de conocimientos y para el desarrollo de determinadas capacidades, pero no para mejorar las capacidades propias del proceso de decisión. Es, siempre según (ARGANDOÑA RAMIZ, 1999), justo en la ética donde el método del caso adquiere más ventajas aunque no queda exento de inconvenientes, generalmente provocados por la complejidad de las situaciones planteadas.

\subsection{Antecedentes. Marco de desarrollo. La asignatura.}

La experiencia se desarrolla en el marco de la asignatura Deontología y Profesionalismo perteneciente al grado en Informática, con código 11550, en adelante DyP. Esta asignatura siete grupos en formato presencial y uno en formato de docencia inversa, impartido en el doble grado de Administración de Empresas e Informática. La asignatura DyP trata de aproximar los contenidos relativos a la profesión informática (marcos profesionales empleados en la Unión Europea), de la legislación informática más relevante y el marco deontológico de la profesión informática a los alumnos, contenidos distribuídos en 4,5 créditos ECTS. El impacto del método del caso en docencia inversa ya había sido medido (OLTRA, 2018a), sin embargo, el estudio resulta falto de perspectiva sin hacer una comparativa con los grupos presenciales. Sí que aparece en dicha comunicación una caracterización del perfil diferencial de los estudiantes de dichos grupos, que sigue siendo válida en el curso actual.

Con respecto al perfil de los alumnos participantes, hay que añadir a los datos objetivos recogidos en la tabla que tienen un perfil que se diferencia del resto de alumnos que cursan DyP, en el segundo semestre, matriculados en el grado de informática. La diferencia más cuantificable, quizá la única a nuestro alcance, la tenemos en su nota de acceso a la universidad, distinta pues a pesar de tratarse de la misma asignatura, del mismo centro, se imparte en dos escenarios distintos, por una parte el doble grado ADE+Informática, y por otra el grado de Informática (siendo de un valor 3,3 puntos mayor para los primeros). Otra diferencia que puede considerarse es el distinto momento en que la asignatura les llega: en el primer semestre de su tercer curso del doble grado, frente al segundo semestre de segundo curso en el grado. A nuestros efectos como docentes el resultado más significativo son sus notas finales: ostensiblemente más altas en el doble grado frente al grado (se triplica el porcentaje de sobresalientes, se duplica el de notables y se reduce a cero el número de suspensos y no presentados). Por su interés, este dato lo recuperaremos al final del presente trabajo.

\section{Objetivos}

En la presente experiencia se trata de verificar que diferencias efectivas hay en el aprovechamiento del método del caso en la adquisición de conocimiento de los alumnos, según el modo de impartición de la asignatura, tomando como elemento de medida la nota. 
De forma adicional se considera un factor: la respuesta a las actividades voluntarias (dependientes de la gamificación), para ayudar a caracterizar a las dos poblaciones. El sentido de añadir estos factores es, en lo que respecta a la gamificación como actividad voluntaria, verificar si la diferencia, caso que la hubiere, en los resultados obtenidos aplicando el método del caso se pueden apoyar en una mayor disposición de cara a afrontar tareas por parte del alumnado. La ligazón mayor se genera por el hecho de que los eventos de gamificación van ligados al desarrollo de casos.

Cabe reseñar aquí un objetivo que no es del presente trabajo, pero ligado al espíritu de permanente contacto con la realidad de la asignatura. Éste no es más que la enseñanza del método en sí mismo (para que los alumnos puedan emplearlo en su vida profesional). Por ejemplo, para su uso en la investigación, como indica (MARTÍNEZ CARAZO, 2006), que subraya su uso tradicional para las investigaciones exploratorias, a las que añade estudios descriptivos y explicativos que permiten la contrastación y generación de teorías, considerándolo un método apropiado para temas que se consideran prácticamente nuevos.

\section{Desarrollo de la innovación}

En las dos modalidades de la asignatura, convencional o presencial pura y flip-teaching, se empleó el método del caso. No abundaremos en descripciones sobre la mecánica del flip-teaching, pero por su naturaleza la imagen de presencialidad absoluta, de clase que es mera exposición y que solo preocupa en casa a la hora de sentarse a estudiar, imagen que solo desaparece cuando el alumno se encierra para enfrentarse a los exámenes finales, desaparece, por las distintas tareas tanto síncronas como asíncronas que el alumno va realizando si desea tener la asignatura «al día». Con respecto a las actividades de aula ligadas al desarrollo de casos, las diferencias fueron solo cuantitativas: en la modalidad de flip-teaching se programan cinco casos para uso en aula, con una duración de debate de 30 a 60 minutos, y en el formato puramente presencial se realizan solo los tres casos con una duración de debate de 30 minutos. Los casos con larga duración tenían una calificación de un punto, mientras que los casos que compartían las dos modalidades, tenían el peso de 0,5 puntos cada uno. El hecho de poder «sacar del aula» buena parte de la teoría nos permite jugar con una holgura de tiempo que invertimos en esa ampliación de trabajo en clase, con los alumnos entregados no a la escucha de un busto parlante, sino participando, debatiendo, construyendo.

Añadamos que cada uno de estos casos llevaba asociada una actividad de gamificación. No abundamos en el desarrollo de la misma, pues es algo que fue tratado en ediciones anteriores de In Red (OLTRA et al, 2016), (OLTRA, 2018b). Si conviene recordar de esos trabajos pretéritos, para evitarle al lector una consulta a los mismos, que la gamificación se lleva a cabo tanto dentro como fuera del aula, en ambas modalidades de docencia en la asignatura. Se trata de un apoyo importante para el docente pues sirve para no solo mantener la tensión tanto dentro como fuera del aula hacia los contenidos impartidos, sino como un pequeño complemento a la nota que sirve sobre todo para los dos casos extremos de alumno: el alumno que va rezagado y necesita de unas pocas décimas siempre para redondear su nota, y el que lucha por la matrícula de honor, que no deja escapar una sola ocasión de arañar un poco más de nota. Para información adicional sobre la mecánica concreta de la misma en nuestra experiencia, nos remitimos a los mismos.

La tabla siguiente nos muestra un resumen de la actividad relativa a la gamificación y los resultados académicos de los casos. Los datos que aparecen en las columnas de «nota media» no precisan mayor explicación en lo que respecta al mecanismo de obtención. La «participación en Gamificación», por el contrario, merece unas palabras al respecto. El porcentaje nos indica, del total de alumnos no matriculados, sino que realmente cursaban la asignatura (excluidos los no presentados) han tomado parte en alguna actividad extra derivada del caso visto en el aula. La exclusión de los no presentados, dado que 
ninguno de los alumnos de docencia inversa figura con esa etiqueta, refuerza aún más la preeminencia de éstos.

Tabla 1. Resumen de la actividad relativa a la gamificación y resultados académicos de los casos

\begin{tabular}{|l|l|l|l|l|}
\hline & $\begin{array}{l}\text { Presencial - nota } \\
\text { media }\end{array}$ & $\begin{array}{l}\text { Doc. Inversa - } \\
\text { nota media }\end{array}$ & $\begin{array}{l}\text { Presencial } \\
\text { participación en } \\
\text { Gamificación. }\end{array}$ & $\begin{array}{l}\text { Doc- Inversa - } \\
\text { Participación en } \\
\text { Gamificación. }\end{array}$ \\
\hline Caso 1 (0,5 p.) & 0,29 & 0,34 & $19,4 \%$ & $22 \%$ \\
\hline Caso 2 (1 pto.) & & 0,51 & & $28 \%$ \\
\hline Caso 3 (0,5 p) & 0,29 & 0,31 & $7 \%$ & $17 \%$ \\
\hline Caso 4 (1 p.) & & 0,77 & $6,2 \%$ & $19 \%$ \\
\hline Caso 5 (0,5 p.) & 0,34 & 0,33 & $10,8 \%$ & $19,4 \%$ \\
\hline $\begin{array}{l}\text { Global (nota sobre } \\
10)\end{array}$ & 6,1 & 6,5 & & \\
\hline
\end{tabular}

Fuente: Elaboración propia

Analizaremos esta tabla en el apartado de resultados.

El modo de llevar a cabo la experiencia fue la realización de un debate en el aula, seguido de un test sobre los resultados obtenidos en el mismo, que servía de evaluación del mismo. En el debate aparecían aspectos, derivadas del tema, muy interesantes, que fueron objeto de gamificación dentro y fuera del aula (mediante Twitter). Para más información de este desarrollo, remitimos al lector a nuestro trabajo anterior (OLTRA et al, 2016). Para llevar a cabo el debate se emplearon en ambas modalidades las pautas, ya clásicas, de (HAMMOND, 2006):

1. Leer el caso superficialmente tomando nota de:

a. ¿De qué se trata el caso?

b. ¿De qué información dispongo para analizarlo? (material de la asignatura, etc.)

2. Leer el caso en profundidad, tomando nota de los elementos clave

a. Problemas a resolver

b. Participantes.

3. Revisar de Nuevo el caso considerando los elementos clave, centrándose en ellos.

4. Crear una lista de lo más destacado en cada uno de los problemas a resolver.

5. Hacer un análisis considerando la teoría de la asignatura.

6. Desarrollar un conjunto de recomendaciones y acciones a tomar.

7. Debatirlas buscando soluciones aceptadas por todos.

Sobre cómo realizarlo, hemos visto distintas vertientes. Es cierto, que, como dicen (EDELSTEIN \& W. DE CAMILLONI, 1996), en un momento dado se produjo un discurso tecnocrático que fue ampliamente difundido en el mundo educativo, simplificándolo para hacerlo viral, definiendo los pasos de forma férrea 
dando poca libertad de actuación al docente. La opción tomada se escapa de un control mayor que el ya expuesto, propuesto por (HAMMOND, 2006), para centrarnos en los objetivos buscados, esto es, la adquisición de competencias por parte de los estudiantes, escapando así de la idea del docente como ingeniero conductual que debe tener mucho más dominio del modelo que, en nuestro caso, los aspectos legales y deontológicos de la informática. Dado que buscamos transmisión de conocimientos, entre otras cosas (¿cómo puede transmitir algo quien carece de ello?), se explica así que empleemos el método del caso como herramienta y no fin en sí mismo.

En nuestra experiencia en particular se emplearon casos reales anonimizados, buscando respuestas a problemas profesionales de no sencilla solución, donde no hay una respuesta correcta, sino varias posibles que, en cualquier caso, según las opciones tomadas para su resolución, pueden tener efectos negativos sobre el profesional, su organización, los clientes o la sociedad en general, desde una perspectiva de espectador que tiene un conocimiento global del problema. Puede abundarse en esto siguiendo nuestro anteriores trabajos (OLTRA, 2017), (OLTRA, 2018b).

\section{Resultados}

En la tabla 1, sin necesidad de aparto estadístico alguno, puede comprobarse, simplemente atendiendo a los casos que comparten ambas modalidades (1, 3 y 5) que tanto en lo que respecta a la nota media obtenida como en la interactividad en la participación, el grupo que recibe la formación como docencia inversa resulta mucho más participativo (casi duplica la actividad), si bien la nota solo tiene una subida mínima (menos de medio punto). Sin embargo, hay que añadir, aunque escape al fin del presente trabajo, que esa ligera subida de nota es extensiva al resto de actividades de la asignatura, conformando, como suma global, una media de nota significativamente más elevada.

Razones pueden encontrarse muchas desde un prisma meramente subjetivo, lo que debería en futuros trabajos medido mediante algún mecanismo de recogida de información al respecto, tales como encuestas realizadas a fin de curso. Podría argumentarse que los alumnos de docencia inversa están acostumbrados a trabajar en clase, pues la clase magistral se reduce a la mínima expresión; sin embargo, ese mismo criterio podría blandirse para razonar en sentido contrario: los alumnos con docencia puramente presencial podrían encontrar en esas sesiones un desahogo.

Adelantábamos un dato que resulta realmente impactante, y que es el que creemos da la medida del éxito en la iniciativa (como se ha ido pudiendo traslucir, nada simple y si compleja, donde la gamificación y el método del caso son solo dos de las caras, importantes, pero solo dos, del poliedro): las notas obtenidas son ostensiblemente más altas en el grupo donde se practica la experiencia de docencia inversa, frente a los datos medios del conjunto de los grupos. Destaquemos:

- $\quad$ El porcentaje de sobresalientes, se triplica.

- El porcentaje de notables, se duplica.

- $\quad$ El número de suspensos y no presentados se reduce a cero.

Este último dato es el que ha resultado más gratificante. Año tras año, el número de no presentados, alumnos que deciden no acudir a examen, ha oscilado entre un $5 \%$ y un $10 \%$. Siempre queda la idea, sin poder confrontarla con la realidad, de que han sido un fracaso para el docente que no ha sabido prepararlos y/o darles confianza en esa preparación para presentarse a las pruebas finales. Pues bien: de ahí el destacar el dato como tremendamente positivo: no solo no ha habido alumnos no presentados sino que, además de confianza, tenían conocimiento: ninguno suspendió.

Nos queda saber si el impacto de la gamificación, al que hemos hecho referencia vinculada únicamente a los casos, ha sido responsable de ese incremento de notas. Es una reflexión que no es baladí, pues una de 
las dudas que atendía de mis compañeros docentes era si con esto estaba de forma encubierta regalando puntos y subiendo artificialmente la nota.

De forma previa a manejar datos reales, mi respuesta iba ligada siempre a una percepción entonces subjetiva: con la gamificación se busca incrementar la participación, pero en realidad es un caramelo con poco azúcar, da realmente muy poco en la nota final. Es cierto que quien participa mucho puede arañar casi un punto, pero no deja de serlo que ese tipo de alumno suele acabar con un sobrante en su nota: son alumnos que luchan por una matrícula de honor (este año, por ejemplo, dos alumnos gracias a la gamificación y, sobre todo, a sus excelentes participaciones, superaron la meta totémica de los 10 puntos); pero no es menos cierto que en realidad el acumulado, para el alumno medio, es de muy pocas décimas. De hecho, tomando la media de los grupos, en el grupo donde se empleó docencia inversa, la gamificación suponía 0,13 puntos en el montante final de la nota, mientras que para el común de los grupos, que no aplicaban docencia inversa, la cifra es aún menor:0,09. Es decir: a efectos de nota final, la gamificación solo ha subido de media una décima de punto al alumno pero, sin embargo, le ha mantenido la tensión hasta la última actividad.

\section{Conclusiones}

La primera y principal conclusión es que el resultado en los alumnos que han cursado la asignatura como docencia inversa ha sido mejor en todos los aspectos frente a aquellos con docencia presencial. No solo han sacado mejor nota en los casos (sin excepción) en los que coinciden, sino que en la nota total de la asignatura también han ido por delante. Una parte de esa nota superior se explica también por su mayor implicación y participación en las actividades de gamificación. Tangencialmente, hemos aludido también a un elemento que al docente no puede serle indiferente: el abandono del alumno (el clásico no presentado) desaparece en éstos.

Pendiente para posteriores estudios queda analizar los motivos de esa mayor implicación. Causas posibles hay muchas, pero de momento quedan bajo una visión puramente subjetiva. Además de las apuntadas en el apartado de resultados, cabría preguntarse por la relación con otras asignaturas (cuales se imparten siguiendo el mismo modelo), su currículum académico, etc. Tal vez el instrumento principal para hacer eso sea una encuesta, en cuyo diseño estamos trabajando en el momento de redactar estas líneas.

\section{Referencias}

ARGANDOÑA RAMIZ, A. (1999).” La enseñanza de la ética por el método del caso. Europa, ¿mercado o comunidad? : de la Escuela de Salamanca a la Europa del futuro" en VI Conferencia Anual de Ética, Economía y Dirección. Salamanca: USAL. (págs. 217-236)

EDELSTEIN, G., \& W. DE CAMILLONI, A. (1996). "Un capítulo pendiente: el método en el debate didáctico contemporáneo" en Corrientes Didácticas. México: Paidos. (págs. 75-90)

HAMMOND, J. S. (2006). "Aprender con el "Método del Caso"” en Harvard Business School, 1-8. $<$ https://www.coursehero.com/file/23314349/HBS-Metodo-del-Caso/> [Consulta: 15 de enero de 2020]

MARTÍNEZ CARAZO, P. C. (2006). "El método de estudio de caso: estrategia metodológica de la investigación científica". Pensamiento \& Gestión (20), 165-193. Julio 2006 $<$ https://www.redalyc.org/articulo.oa?id=64602005 > [Consulta: 15 de enero de 2020]

OLTRA GUTIÉRREZ, J. V. (2017). "Evaluación en FLIP-Teaching: una alternativa a los exámenes parciales. Evaluación continua mediante tareas y casos" en In-Red 2017. III Congreso Nacional de 
innovación educativa y de docencia en red (págs. 641-649). Valencia: Universitat Politècnica de València.

OLTRA GUTIÉRREZ, J. V. (2018). "Gamificación e Informática. Comparativa de una experiencia mixta en Grado y Máster" en IN-RED 2018. IV Congreso Nacional de Innovación Educativa y Docencia en Red. Valencia: Universitat Politècnica de València.

OLTRA GUTIÉRREZ, J. V. (2018). "Método del caso como medio de evaluación dentro del modelo FLIP-Teaching. Una experiencia con una asignatura de corte jurídico para ingenieros" en IN-RED 2018. IV Congreso Nacional de Innovación Educativa y Docencia en Red (págs. 492-501). Valencia: Universitat Politècnica de Valéncia.

OLTRA GUTIÉRREZ, J. V., GARRIGÓS SIMÓN, F., \& NARANGAJAVANA, Y. (2016). "Introducción de actividades de Gamificación en una asignatura humanista para informáticos" en In-Red 2016. II Congreso nacional de innovación educativa y docencia en red. Valencia: Universitat Politècnica de València.

TOLLER, F. M. (2005). "Orígenes históricos de la educación con el método del caso". Anuario da Facultade de Dereito da Universidade da Coruña, $\mathrm{n}^{\mathrm{o}}$ 9, 921-944. $<$ https://dialnet.unirioja.es/servlet/articulo?codigo=1416448> [Consulta: 15 de enero de 2020] 